\title{
Wideband and high gain dielectric resonator antenna for 5G applications
}

\author{
Irfan Ali ${ }^{1}$, Mohd Haizal Jamaluddin ${ }^{2}$, M. R. Kamarudin ${ }^{3}$, Abinash Gaya ${ }^{4}$, R. Selvaraju ${ }^{5}$ \\ ${ }^{1,2,4,5}$ Wireless Communication Centre, School of Electrical Engineering, Faculty of Engineering, \\ Universiti Teknologi Malaysia, Malaysia \\ ${ }^{3}$ Centre for Electronic Warfare Information and Cyber, Cranfield Defence and Security, \\ Cranfield University, United Kingdom
}

\begin{tabular}{l}
\hline \hline Article Info \\
\hline Article history: \\
Received Feb 9, 2019 \\
Revised Mar 29, 2019 \\
Accepted Apr 12, 2019 \\
\hline
\end{tabular}

Keywords:

$5 \mathrm{G}$

Dielectric resonator antenna

High gain

Higher order mode

Perforated

Wideband

\begin{abstract}
In this paper, wideband high gain dielectric resonator antenna for $5 \mathrm{G}$ applications is presented. Higher order $T E_{\delta 15}^{x}$ mode is exploited to enhance the antenna gain, while the array of symmetrical cylindrical shaped holes drilled in the DRA to improves the bandwidth by reducing the quality factor. The proposed DRA is designed using dielectric material with relative permittivity of 10 and loss tangent of 0 . 002. The Rogers RT/Droid 5880 has been selected as substrate with relative permittivity of 2.2 , loss tangent of 0.0009 - and $0.254-\mathrm{mm}$ thickness. The simulated results show that, the proposed geometry has achieved a wide impedance bandwidth of $17.3 \%$ $(23.8-28.3 \mathrm{GHz}=4.5 \mathrm{GHz})$ for $\mathrm{S} 11<-10 \mathrm{~dB}$, and a maximum gain of about 9.3 $\mathrm{dBi}$ with radiation efficiency of $96 \%$ at design frequency of $26 \mathrm{GHz}$. The DRA is feed by $50 \Omega$ microstrip transmission line with slot aperture. The reflection coefficient, the radiation pattern, and the antenna gain are studied by full-wave EM simulator CST Microwave Studio. The proposed antenna can be used for the $5 \mathrm{G}$ communication applications such as device to device communication (D2D).
\end{abstract}

Copyright $@ 2019$ Institute of Advanced Engineering and Science. All rights reserved.

\section{Corresponding Author:}

Mohd Haizal Jamaluddin,

Wireless Communication Centre, School of Electrical Engineering,

Universiti Teknologi Malaysia, Johor Bahru 81310, Malaysia.

Email: haizal@fke.utm.my

\section{INTRODUCTION}

Wireless communication technology is a rapidly growing field of telecommunication industry. Currently, 5G is considered as a next generation wireless technology. Dynamic research has been conducted throughout the world to advance the future generation $(5 \mathrm{G})$ wireless communication. The successful deployment of $5 \mathrm{G}$ communication demand low cost, compact and efficient antennas. In this regard, antenna research community has shown great interest in designing such antennas. Since the last few years, Microstrip antennas and dielectric resonator antennas have been extensively studied. Microstrip antennas are good candidate for future generation communication because of its small size, light weight, and ease of fabrication. However, microstrip antennas suffer from severe metallic losses and surface wave excitation at higher frequencies. In contrast, DRA has received a great attention by researchers due to its potential advantages like low profile, light weight, wide bandwidth, ease of excitation schemes and high radiation efficiency in the absence of conductor losses even at higher frequencies [1-5]. DRA is made of dielectric material with no conductor losses [6]. Therefore, Dielectric resonator antenna has a great potential to replace the traditional low gain metallic antennas such as microstrip patch antennas and found to be a most suitable candidate [7]. DRA comes in various shapes such as cylindrical [8], hemi-spherical [9], rectangular [10-12], triangular [13] and others shapes $[14,15]$. Another feature of DRA is flexible excitation schemes which are used to feed 
the DRA such as microstrip feed line [16], probe feed [17, 18], co-planar wave guide [19], dielectric image guide [20], slot aperture [21, 22].

Various techniques have been proposed to enhance the gain and bandwidth of DRA. Stacked DRA [23, 24], proposed to enhance the gain and bandwidth. Placing a surface mounted short horns around the DRA [25] has also been used to increase the gain and bandwidth. However, these approaches have either large surface area, or limited gain, which are not suitable for future communication systems applications. Recently, higher order modes were used only to enhance the gain of DRA [26], however this approach has major drawback of narrower bandwidth. In this paper, the main goal is to achieve wider impedance bandwidth with high gain using the concept of higher order mode at $26 \mathrm{GHz}$. Array of symmetrical cylindrical holes drilled uniformly in the DRA for bandwidth improving operating on the higher order $T E_{\delta 15}$ radiating mode. The novelty of this approach of bandwidth improvement lies in contrast with the fundamental mode, the DRA is excited with the higher order mode.

\section{ANTENNA DESIGN}

The configuration of the proposed DRA with array of symmetrical cylindrical holes operating on higher order mode is illustrated in Figure 1. DRA is excited using a microstrip transmission line through a coupled rectangular slot etched on ground plane. DR ECCOCK HiK TEK material having dielectric constant of $\varepsilon_{r}=10$, loss tangent of $\tan \delta=0.002$ with dimensions of length, width and height $(a \times b \times d)$ is designed to operate at the resonance frequency of $26 \mathrm{GHz}$. Dielectric resonator is located on small ground plane $(\mathrm{Wg}$ and $\mathrm{Lg}=11.5 \mathrm{~mm} \times 11.5 \mathrm{~mm}$ ) as depicted in Figure 1. A substrate RT/Duroid 5880 with relative permittivity of 2.2 , loss tangent $\tan \delta$ of 0.0009 and thickness of $0.254 \mathrm{~mm}$ is used. The dimensions of the proposed structure are given in Table 1.

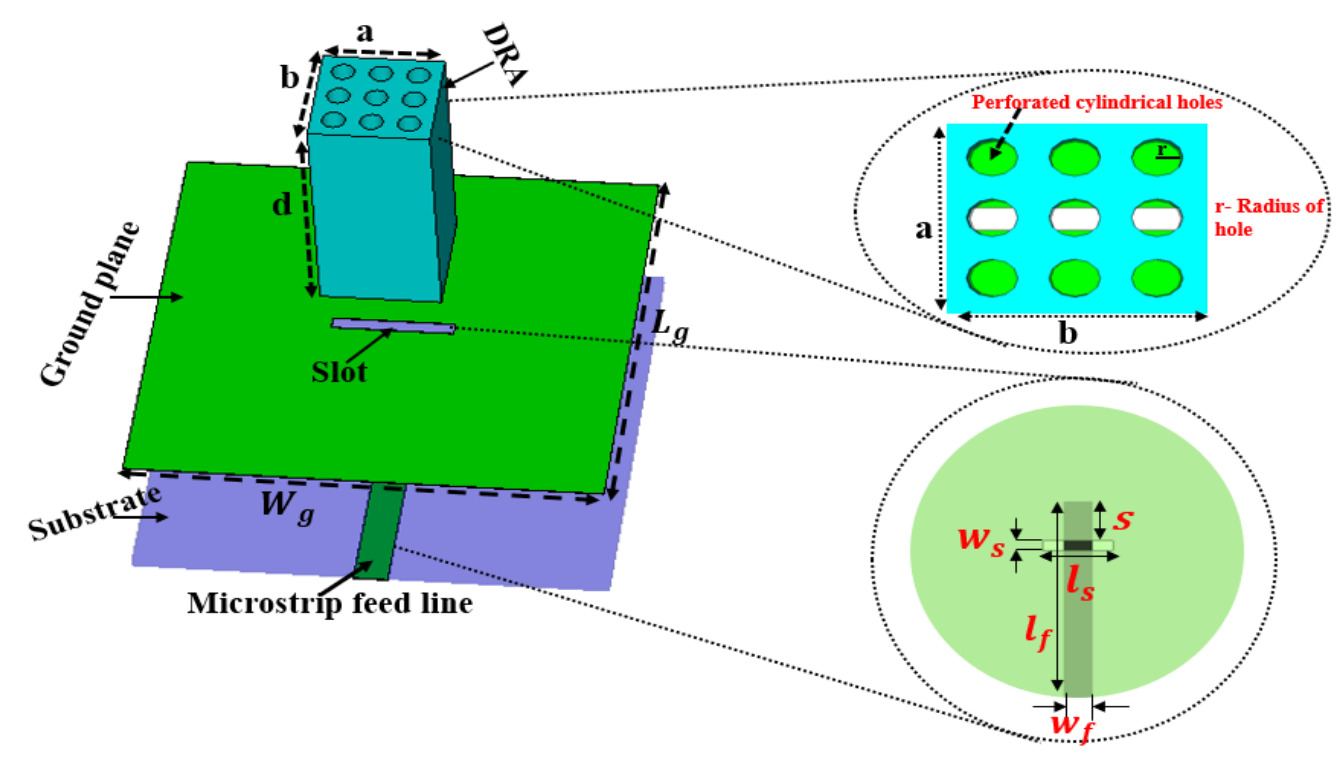

Figure 1. Geometry of the proposed DRA

\section{RESULTS AND DISCUSSIONS}

The proposed DRA operating in the higher order $T E_{\delta 15}^{x}$ mode is simulated using CST MWS. The higher order mode improves the gain of an antenna, but it has narrower bandwidth. The dielectric resonator antenna bandwidth can be improved at higher order mode by lowering down the quality factor. The symmetrical array of cylindrical holes are drilled on the DRA to reduce the quality factor, thus increases impedance bandwidth. The size of the cylindrical holes and distance between the two holes are maintained with radius of $0.28 \mathrm{~mm}$ and $0.34 \mathrm{~mm}$, respectively while the height of the cylindrical hole is same as the height of the DRA as mentioned in Table 1. It is clearly indicated from (1) and (2) that, bandwidth increases with perforations by lowering the quality factor. The $\mathrm{Q}$ factor and bandwidth are inversely proportional to each other. 


$$
\begin{aligned}
& Q=2 \omega_{0} \frac{\text { Stored energy }}{\text { Radiated power }} \propto 2 \omega_{0}\left(\varepsilon_{\text {eff }}\right)^{p}\left(\frac{\text { Volume }}{\text { Surface }}\right)^{s} \text { with } p>s \geq 1 \\
& B W=\frac{V S W R-1}{Q \sqrt{V S W R}}
\end{aligned}
$$

Table 1. Optimized parameters of the perforated DRA operating on $T E_{115}^{x}$ mode

\begin{tabular}{lllllllc}
\hline Resonant mode & $a$ & $b$ & $d$ & $w_{s}$ & $l_{s}$ & $s$ & $r$ \\
\hline$T E_{\delta 15}$ mode & 2.91 & 2.91 & 6.1 & 0.35 & 2.95 & 1.3 & 0.28 \\
\hline $\begin{array}{l}a, b \text { and } d \\
\text { s=length of stub, r=radius of cylindrical hole. }\end{array}$
\end{tabular}

Figure 2 shows the simulated $|\mathrm{S} 11|$ result of the proposed antenna. It can be seen from the Figure 2 that, the proposed antenna exhibits a wide impedance bandwidth of $17.3 \%$ (4.5 GHz), ranging from 23.8 $\mathrm{GHz}$ to $28.3 \mathrm{GHz}$. The antenna gain and radiation efficiency versus frequency is plotted in Figure 3 . The simulated maximum gain of $9.28 \mathrm{dBi}$ is achieved with radiation efficiency of $96 \%$ at $26 \mathrm{GHz}$ frequency. Figure 4 shows the simulated 3D radiation pattern at operating frequency of $26 \mathrm{GHz}$. Figure 5 shows the simulated normalized radiation patterns of the DRA in both the E-and H-planes at $26 \mathrm{GHz}$. As depicted in Figure 5, the pattern shows a broadside radiation characteristic over the entire impedance bandwidth. The results of the proposed antenna is given in Table 2.

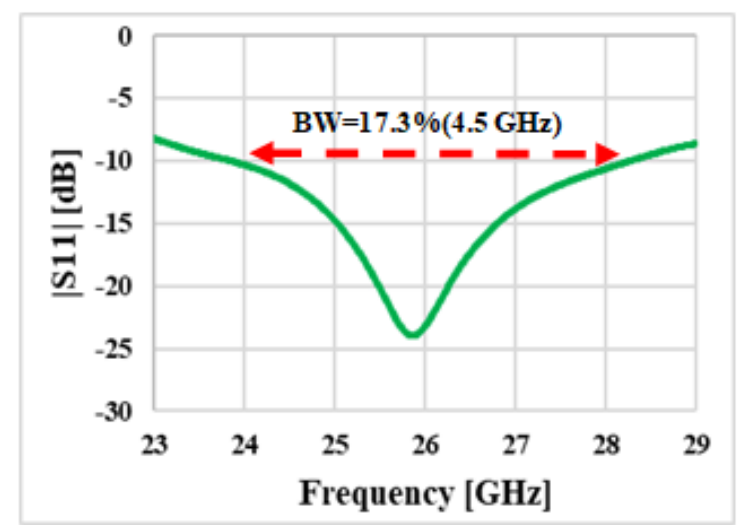

Figure 2. Simulated $|\mathrm{S} 11|$ of the DRA at $26 \mathrm{GHz}$

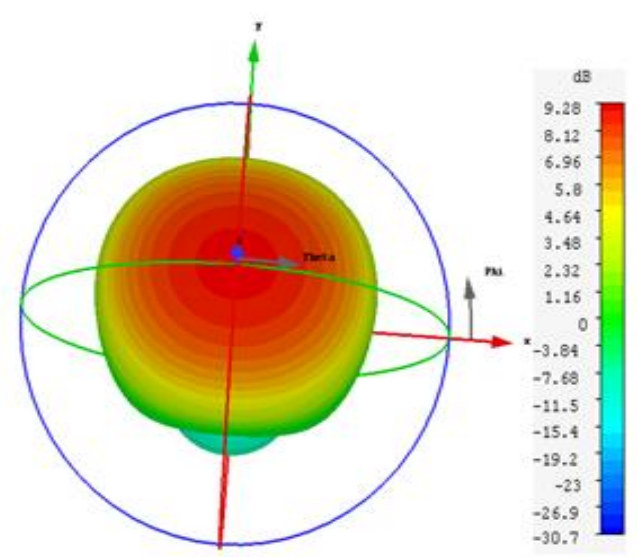

Figure 4. Simulated 3D radiation pattern

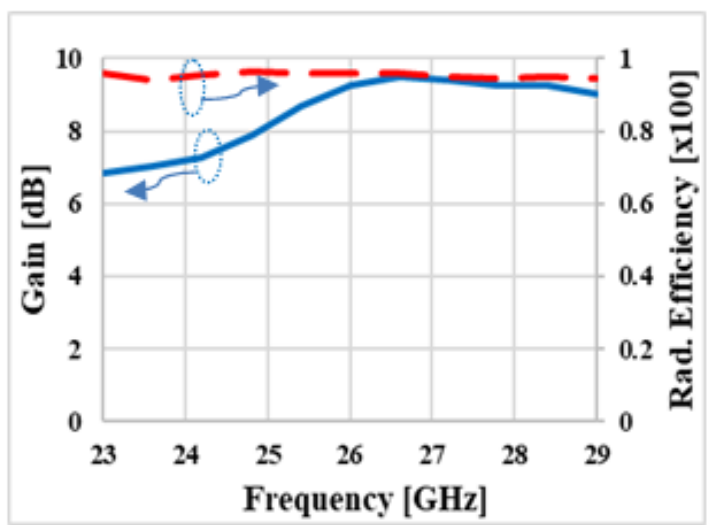

Figure 3. Gain and efficiency Vs radiation efficiency at $26 \mathrm{GHz}$

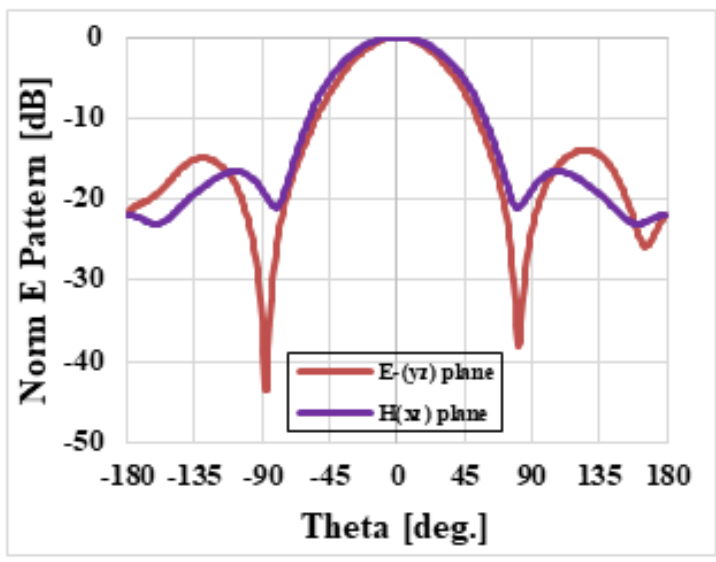

Figure 5. Simulated normalized radiation pattern in the $\mathrm{E}(\mathrm{yz})$ and $\mathrm{H}(\mathrm{xz})$ 


\begin{tabular}{ccccc}
\multicolumn{4}{c}{ Table 2. Summary of simulated results of proposed structure } \\
\hline Mode & $\boldsymbol{f}_{\boldsymbol{r}}(\boldsymbol{G H z})$ & $\mathrm{BW}(\%)(\boldsymbol{S 1 1}-\mathbf{1 0} \boldsymbol{d B})$ & Gain $(\mathrm{dBi})$ & Efficiency $(\%)$ \\
\hline $\boldsymbol{T} \boldsymbol{E}_{\boldsymbol{\delta} \mathbf{1 5}}$ mode & 26 & $23.8-28.3=4.5(17.3 \%)$ & 9.28 & 96 \\
BW, bandwidth in percentage; $\boldsymbol{f}_{\boldsymbol{r}}$, resonant frequency in GHz. & & \\
\hline
\end{tabular}

\section{CONCLUSION}

A perforated DRA operating in the higher order mode is designed to obtain wideband and high gain at the frequency of $26 \mathrm{GHz}$ is presented in this paper. The simulated results of the proposed antenna showed a wider impedance bandwidth of $17.3 \%(4.5 \mathrm{GHz})$ ranging from $23.8 \mathrm{GHz}$ to $28.3 \mathrm{GHz}$. The maximum gain achieved is $9.2 \mathrm{dBi}$ with radiation efficiency of $96 \%$. The proposed antenna is suitable for device to device communication in Internet-of-Things (IoT) for 5G applications.

\section{ACKNOWLEDGEMENTS}

The authors would like to thank the Ministry of Higher Education (MOHE) under FRGS (vote 4F283 and 4F733) and under Research University Grant (votes 19H56 and 03G59) and Science fund Grant (Vot.No.4S134) and Higher Centre of excellence Grant (vote 4J220) for supporting this research work.

\section{REFERENCES}

[1] Petosa A. Dielectric Resonator Antenna Handbook. Norwood, MA:Artech House; 2007. 308 p.

[2] K.M.Luk, K.W.Leung. , "Dielectric Resonator Antennas. Leung DRAE by KML and KW, 12., editors. Bal- dock, U.K., Research Studies Press,; 2003. 388 p.

[3] A. Petosa and A. Ittipiboon, "Dielectric Resonator Antennas: A Historical Review and the Current State of the Art," in IEEE Antennas and Propagation Magazine, vol. 52, no. 5, pp. 91-116, Oct. 2010.

[4] Keyrouz S, Caratelli D. Dielectric Resonator Antennas: Basic Concepts, Design Guidelines , and Recent Developments at Millimeter-Wave Frequencies. Int J Antennas Propag. 2016;2016.

[5] R. K. Mongia and P. Bhartia. "Dielectric resonator antennas-A Review and General Design Relation for Resonant Frequency and Bandwidth,." Int J Microw Millim Wave Comput Eng. vol 4, no. 3, pp. 230-247, 1994.

[6] N. H. Shahadan et al., "Steerable Higher Order Mode Dielectric Resonator Antenna With Parasitic Elements for 5G Applications," in IEEE Access, vol. 5, pp. 22234-22243, 2017.

[7] Nasir J, Jamaluddin MH, Khalily M, Kamarudin MR, Ullah I, Selvaraju R. A reduced size dual port MIMO DRA with high isolation for 4G applications. Int J RF Microw Comput Eng, vol. 25, no. 6, pp. 495-501, 2015.

[8] Guha D, Antar YMM. Four-element cylindrical dielectric resonator antenna for wideband monopole-like radiation. IEEE Trans Antennas Propag, vol. 54, no. 9, pp. 2657-2662, 2006.

[9] Mukherjee B, Patel P, Mukherjee J. A novel hemispherical dielectric resonator antenna with complementary splitring-shaped slots and resonator for wideband and low cross-polar applications. IEEE Antennas Propag Mag., vol. 57, no. 1, pp. 120-128, 2015.

[10] M.W. McAllister; S.A. Long; G.L. Conway. Rectangular dielectric resonator antenna. Electron Lett., vol. 19, no. 6, pp. 218-219, 1983.

[11] Nor NM, Jamaluddin MH, Kamarudin MR, Khalily M. Rectangular Dielectric Resonator Antenna Array for 28 GHz Applications. Prog Electromagn Res, vol. 63, pp. 53-61, 2016.

[12] Nasir J, Jamaluddin MH, Khalily M, Kamarudin MR, Ullah I. Design of an MIMO Dielectric Resonator Antenna for 4G Applications. Wireless Personal Communications, vol. 88, no. 3, pp. 525-536, 2016.

[13] H. Y. Lo, K. W. Leung, K. M. Luk and E. K. N. Yung, "Low profile equilateral-triangular dielectric resonator antenna of very high permittivity," in Electronics Letters, vol. 35, no. 25, pp. 2164-2166, 9 Dec. 1999.

[14] Q. Rao, T. A. Denidni and A. R. Sebak, "Broadband compact stacked T-shaped DRA with equilateral-triangle cross sections," in IEEE Microwave and Wireless Components Letters, vol. 16, no. 1, pp. 7-9, Jan. 2006.

[15] R. Chair, A. A. Kishk, K. F. Lee and C. E. Smith, "Wideband flipped staired pyramid dielectric resonator antennas," in Electronics Letters, vol. 40, no. 10, pp. 581-582, 13 May 2004.

[16] T. A. Denidni and Z. Weng, "Rectangular dielectric resonator antenna for ultrawideband applications," in Electronics Letters, vol. 45, no. 24, pp. 1210-1212, 19 November 2009.

[17] Y. Pan, K. W. Leung and K. Lu, "Compact Quasi-Isotropic Dielectric Resonator Antenna With Small Ground Plane," in IEEE Transactions on Antennas and Propagation, vol. 62, no. 2, pp. 577-585, Feb. 2014.

[18] Adam P. Huynh, David R. Jackson, Stuart A. Long, Donald R. Wilton, A study of the impedance and pattern bandwidths of aperture-coupled cylindrical dielectric resonator antennas, Microwaves and Optical Technology Letters, pp. 56, no. 9, pp. 2129-2132, 2014.

[19] K. S. Ryu and A. A. Kishk, "UWB Dielectric Resonator Antenna Having Consistent Omnidirectional Pattern and Low Cross-Polarization Characteristics," in IEEE Transactions on Antennas and Propagation, vol. 59, no. 4, pp. 1403-1408, April 2011. 
[20] A. S. Al-Zoubi, A. A. Kishk and A. W. Glisson, "A Linear Rectangular Dielectric Resonator Antenna Array Fed by Dielectric Image Guide With Low Cross Polarization," in IEEE Transactions on Antennas and Propagation, vol. 58, no. 3, pp. 697-705, March 2010.

[21] O.M.H. Ahmed, A.R. Sebak, T.A. Denidni, Compact UWB printed monopole loaded with dielectric resonator antenna. Electronics Letters, vol. 47, no. 6, pp. 7-8, January 2011.

[22] Shahadan NH, Kamarudin MR, Jamaluddin MH. Investigation on Feeding Techniques for Rectangular Dielectric Resonator Antenna in Higher-Order Mode for 5G Applications. Applied Mechanics and Materials, vol, 781, pp. 4144, 2015.

[23] Luk KM, K. W. Leung and KYC. Bandwidth and Gain Enhancement of a Dielectric Resonator Antenna With the Use of a stacking element. Microwaves and Optical Technology Letters, vol. 14, no. 4, pp. 215-217, 1997.

[24] Y. M. Pan and S. Y. Zheng, "A Low-Profile Stacked Dielectric Resonator Antenna With High-Gain and Wide Bandwidth," in IEEE Antennas and Wireless Propagation Letters, vol. 15, pp. 68-71, 2016.

[25] Nasimuddin and K. P. Esselle, "Antennas with dielectric resonators and surface mounted short horns for high gain and large bandwidth," in IET Microwaves, Antennas \& Propagation, vol. 1, no. 3, pp. 723-728, June 2007.

[26] A. Petosa and S. Thirakoune, "Rectangular Dielectric Resonator Antennas With Enhanced Gain," in IEEE Transactions on Antennas and Propagation, vol. 59, no. 4, pp. 1385-1389, April 2011.

\section{BIOGRAPHIES OF AUTHORS}

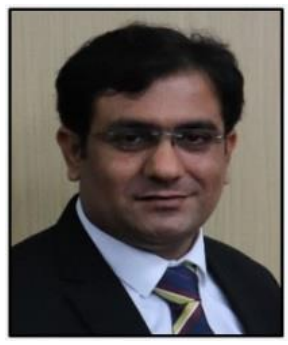

Irfan Ali received the B.E degree in Telecommunications from the Mehran University of Engineering and Technology (MUET), Pakistan, in 2010 and the master's degree in Telecommunications Engineering from NED University of Engineering and Technology in 2014. He is currently pursuing the Ph.D. degree with the Wireless Communication Centre (WCC), Universiti Teknologi Malaysia (UTM). He is a student member in IEEE. His research interests include microstrip patch antennas, dielectric resonator antennas, MIMO antennas, mutual coupling analysis.

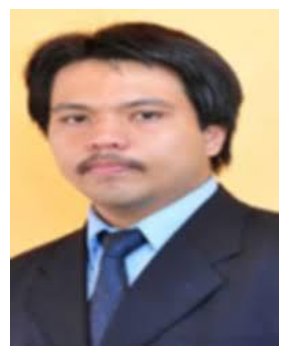

Mohd Haizal Jamaluddin received bachelor's and master's degrees in electrical engineering from Universiti Teknologi Malaysia, Malaysia, in 2003 and 2006, respectively, and the Ph.D. degree in signal processing and telecommunications from the Université de Rennes 1, France, in 2009, with a focus on microwave communication systems and specially antennas such as dielectric resonator and reflectarray and dielectric dome antennas. He is currently an Associate Professor with the Wireless Communication Centre, School of Electrical Engineering, Universiti Teknologi Malaysia. His research interests include dielectric resonator antennas, printed microstrip antennas, MIMO antennas and DRA reflectarray antenns. He has published more than 100 papers in reputed indexed journals and conference proceedings.

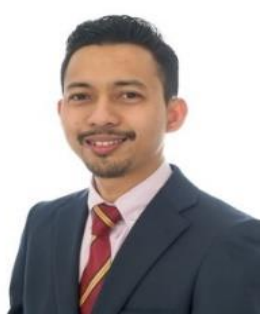

Muhammad Ramlee Kamarudin (M'08- SM'13) received the degree (Hons.) majoring in Electrical and Telecommunication Engineering from Universiti Teknologi Malaysia, Johor Bahru, Malaysia, in 2003, and the MSc degree in Communication Engineering and the Ph.D. degree in Electrical Engineering from the University of Birmingham, Birmingham, U.K., in 2004 and 2007, respectively, under the supervision of Emeritus Professor Peter Hall. He has been a Senior Lecturer with the Centre for Electronic Warfare, Information and Cyber, Cranfield Defence and Security, Cranfield University, U.K., since June 2017. Prior to this appointment, he was an Associate Professor with the Wireless Communication Centre, Universiti Teknologi Malaysia. He holds an H-Index of 21 (SCOPUS) and over 1650 citations (SCOPUS). He has authored a book chapter of a book entitled Antennas and Propagation for Body-Centric Wireless Communications and has published over 220 technical papers in journals and proceedings including the IEEE Transaction on Antennas and Propagation, the IEEE Antennas and Wireless Propagation Letter, the IEEE Antenna Magazine, the IEEE Access, the International Journal of Antennas and Propagation, Progress in Electromagnetic Research, Microwave and Optical Technology Letters, and Electronics Letters. His research interests include antenna design for 5G, MIMO antennas, Array antenna for beam-forming and beam steering, wireless on-body communications, in-body communications (implantable antenna), RF and microwave communication systems, and antenna diversity. He is a Member of IET, an Executive Member of Antenna and Propagation, Malaysia Chapter, and a Member of the IEEE Antennas and Propagation Society, the IEEE Communication Society, the IEEE Microwave Theory and Techniques Society, the IEEE Electromagnetic Compatibility Society, an Associate Editor for Electronics Letters and IET Microwaves, Antennas and Propagation, and an Academic Editor for the International Journal of Antennas and Propagation. 

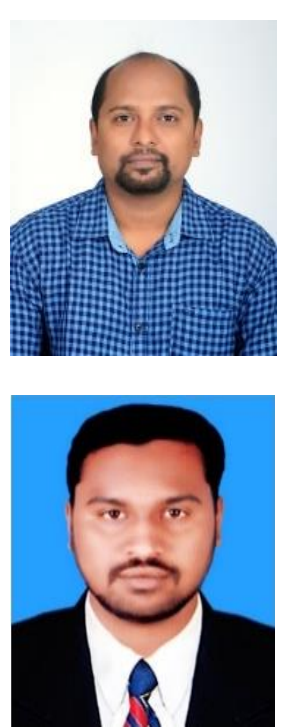

Abinash Gaya is a PhD Student at Wireless Communication Centre (WCC), UTM Johor Bahru. He has been involved in the Design and Development of Dielectric Resonator Antennas for 5G Communications at WCC. He is also working towards Design of Phased Array Antenna system for $5 \mathrm{G}$ Base Stations. He is a student member in IEEE.

Raghuraman Selvaraju was born in Gandarvakottai, Tamilnadu, India, in 1989. He received bachelor's degree in electronics and communication engineering and master's degree in wireless communication systems in 2011 and 2014, respectively from Periyar Maniammai University, India. He is currently pursuing the Ph.D. degree with the Wireless Communication Centre (WCC), Universiti Teknologi Malaysia (UTM). School of Engineering, Universiti Teknologi Malaysia. His research interests include microstrip patch antennas, dielectric resonator antennas, MIMO antennas, beamforming array antennas, mutual coupling analysis, metamaterials, and split ring resonators. 